\title{
Imaginários da masculinidade bem-sucedida e as narrativas de consumo na curadoria jornalística: o medo da despossessão financeira e o elogio à potência em VIP, GQ e L’Officiel Hommes
}

\section{Eliza Bachega Casadei}

Doutora; Escola Superior de Propaganda e Marketing, São Paulo, SP, Brasil

elizacasadei@yahoo.com.br

\section{Resumo}

O objetivo do presente artigo é analisar o medo da despossessão financeira como uma dinâmica estruturante dos imaginários das masculinidades bem-sucedidas presentes no projeto editorial de algumas revistas masculinas contemporâneas, nomeadamente VIP, GQ e L'Officiel Hommes. O medo da perda do poder econômico, nesses termos, nem sempre se faz ver nos lugares mais óbvios, mas implica em uma gestão de afetos positivos que sustentam narrativas de consumo específicas. A partir de uma análise dos lugares comuns das narrativas de êxito financeiro dessas revistas, com os pressupostos metodológicos da frame analysis, podemos inferir que as narrativas do medo da despossessão financeira são sustentadas, em tais produções, pela paixão disruptiva, pelo medo da perda da autonomia e pelo elogio da potência como pilares que sustentam tais imaginários.

\section{Palavras-chave}

Comunicação. Consumo. Masculinidades. Afetividades. Narrativas. 


\section{Introdução}

Dentre as diversas estratégias narrativas utilizadas na imprensa, a exploração do medo ocupa um lugar de destaque. Tal como apontado por Moretzsohn (2003), o medo:

[...] não se restringe à questão criminal, transbordando para os mais distintos temas da vida cotidiana: a carne contaminada, os remédios falsificados, a água imprópria para consumo, os inúmeros golpes com cartões de crédito, tudo é exposto como se o mundo fosse um lugar essencialmente hostil e perigoso, produzindo uma permanente sensação de insegurança em todos os níveis. (MORETZSOHN, 2003, p. 3).

A gestão do imaginário social do medo, nesses termos, “[...] é uma forma de produzir subjetividades, ou melhor, uma forma de controle social através de instâncias simbólicas." (CORRÊA, 2010, p. 94) a partir das formas em que elas são narradas e mediadas socialmente.

Associada à questão do medo, também podemos apontar que há uma racionalidade própria a uma sociedade organizada a partir da circulação de bens, serviços e informação que, para Safatle (2016), “[...] determina as ações dos sujeitos a partir da produção de valor.” (SAFATLE, 2016, p. 142). Sob os imperativos da utilidade, aquele que não produz valor teme ser excluído do conjunto social justamente em função disso. Safatle (2016) chama a atenção para um tipo específico de estrutura social do medo a partir do qual "[...] o supereu mesclaria o medo arcaico da aniquilação física com o 'medo posterior de não pertencer ao conjunto humano' devido ao fracasso de não ser bem-sucedido como sujeito econômico." (SAFATLE, 2016, p. 141). Dessa forma, a partir do momento em que houve um desmantelamento do Estado-providência, "[...] é importante que o discurso social produza a circulação incessante do risco de morte social devido à degradação econômica iminente daqueles que resistem a reconstruir sua vida psíquica a partir da racionalidade econômica vigente." (SAFATLE, 2016, p. 142). As práticas midiáticas, de uma maneira geral, são impactadas por esse imaginário social e articulam suas ações a partir dele.

A partir desses pressupostos, o objetivo do presente artigo é analisar o medo da despossessão financeira como uma dinâmica estruturante do imaginário da masculinidade bem-sucedida presente no projeto editorial de algumas revistas masculinas 
Imaginários da masculinidade bem-sucedida e as narrativas de consumo na curadoria jornalística: o medo da despossessão financeira e o elogio à potência em VIP, GQ e L'Officiel Hommes

contemporâneas. Para isso, utilizaremos como aportes metodológicos os pressupostos da frame analysis (GOFFMAN, 1986), com o objetivo de verificar os enquadramentos noticiosos mais recorrentes quanto a essas temáticas, conforme detalhado no próximo tópico. 0 medo da perda do poder econômico, nesses termos, nem sempre se faz ver nos lugares mais óbvios (em reportagens sobre o desemprego, por exemplo), mas sim, implica em uma gestão de afetos positivos que sustentam narrativas de consumo específicas, conforme discutiremos a seguir. A partir de uma análise dos lugares comuns das narrativas de consumo das revistas masculinas VIP, GQ e L'Officiel Hommes, podemos inferir que as narrativas do medo da despossessão financeira são sustentadas, em tais produções, pela paixão disruptiva, pelo medo da perda da autonomia e pelo elogio da potência como pilares que sustentam tal imaginário.

\section{0 medo da despossessão financeira como uma forma específica de gestão dos afetos}

As revistas VIP, GQ e L'Officiel Hommes possuem uma proposta editorial em comum: fornecer, para o público masculino, uma curadoria jornalística do que, segundo um termo recorrente nas três publicações, seria "o melhor do lifestyle masculino" (PADILLA, 2017b, p. 8). No editorial do mês de outubro de 2017, por exemplo, $G Q$ afirmava que a revista fornecia "o tipo de leitura originada de uma apurada curadoria de lifestyle" (CRUZ, 2017, p. 28.), o que significa, nos termos do editor, que "[...] enumeramos os designers contemporâneos que você precisa conhecer, os arquitetos e personal trainers mais desejados, os maiores gestores e multiplicadores de fortunas, os publicitários mais influentes, os advogados mais poderosos." (CRUZ, 2017, p. 28.)ํ․ No media kit da revista VIP, é possível ler que "VIP é a marca do homem contemporâneo". Para eles,

[...] apresentamos o melhor do lifestyle masculino - as melhores dicas de viagem, gastronomia e cultura, perfis de homens inspiradores, tendências de moda e relojoaria, os principais lançamentos do setor automotivo, cuidados com a saúde, alimentação, grooming e esporte, ensaios com as mulheres mais deslumbrantes do momento. (VIP, 2017, doc. não paginado).

\footnotetext{
${ }^{1}$ No editorial de janeiro de 2018, lê-se que: “A GQ é a única marca internacional multiplataforma de luxo, moda, estilo de vida voltada para o homem brasileiro contemporâneo, o guia para um universo em que o estilo e o bom gosto, em toda sua profundidade e amplitude de significados e entendimentos, são essenciais para uma vida melhor [...] fundamental mesmo é ter estilo." (CRUZ, 2018, p. 20).
} 
Tal como definido por Corrêa e Bertocchi (2012), "Em sua etimologia, o termo curadoria está vinculado ao ato de curar, zelar, vigiar por algo [...]. Com a evolução social o termo passa a relacionar-se com o campo das artes, dos museus e de seus respectivos acervos." (CORRÊA; BERTOCCHI, 2012, p. 4). A curadoria, portanto, refere-se "[...] às atividades de seleção, organização e apresentação de algo a partir de algum critério inerente ao indivíduo curador." (CORREAA; BERTOCCHI, 2012, p. 4). Por curadoria jornalística, portanto, referimo-nos a uma prática jornalística a partir da qual as reportagens se voltam para a recomendação de produtos e serviços para o consumo a partir de critérios de qualidade definidos pelos seus projetos editoriais. As propostas editoriais das três publicações analisadas articulam-se, portanto, em torno da curadoria jornalística de consumo e estilo de vida, a partir de enquadramentos temáticos bem específicos, que serão detalhados a seguir. Nas três revistas, o lifestyle masculino é traduzido, majoritariamente, em curadoria de produtos de luxo para o consumo. 0 editorial de janeiro de 2018 da revista VIP coloca tal orientação em termos bem explícitos:

Pegue sua Harley e vá raspar a pedaleira nas curvas de alguma estrada, sentindo o vento batendo no rosto; faça as malas, suba no seu Volvo XC40 e vá ficar à toa em algum litoral paradisíaco país afora - quem sabe Trancoso, que entra ano, sai ano, continua a praia mais hype do Brasil. E, assim, seja lá aonde for, mantenha o estilo, sempre: use sua melhor camisa de estampa floral, tendência do ano passado que continua com tudo. (PADILLA, 2017a, p. 6)2.

Histórias de resiliência e sucesso (quase que exclusivamente financeiro), o anúncio de produtos e viagens de luxo combinadas com dicas sobre como ganhar mais dinheiro compõem as temáticas centrais em torno das quais VIP, GQ e L'Officiel Hommes compõem a urdidura de seu projeto editorial. A estruturação editorial dessas publicações masculinas, portanto, articula-se em torno de narrativas sobre consumo de luxo e as formas de construção bem-sucedida do sujeito econômico.

\footnotetext{
2 De acordo com o media kit das revistas analisadas (GQ, 2017; L'OFFICIEL HOMMES, 2017; VIP, 2017), em 2017, a tiragem da GQ foi de 33.437 exemplares mensais, com uma projeção de 70 mil leitores, sendo $60 \%$ deles de 25 a 44 anos e $58 \%$ de classe A e B. Já VIP teve tiragem de 48.353 exemplares mensais, com projeção de 414 mil leitores, $69 \%$ deles de classe B e C e $56 \%$ com faixa etária entre 20 e 39 anos. L'Officiel Hommes publica, no Brasil, 4 edições ao ano, com uma tiragem média de 40 mil exemplares. A revista não disponibiliza as porcentagens, mas afirma que a maior parte de seu público leitor são homens solteiros, de classe $\mathrm{A}$ e $\mathrm{B}$, de 25 a 50 anos.
} 
Imaginários da masculinidade bem-sucedida e as narrativas de consumo na curadoria jornalística: o medo da despossessão financeira e o

Para a presente pesquisa ${ }^{3}$, fizemos o mapeamento das temáticas mais recorrentes nas reportagens publicadas nas três publicações analisadas, com recorte temporal nas edições publicadas entre janeiro de 2017 a janeiro de 2018. 0 mapeamento utilizou, como procedimento metodológico, a contagem do número de páginas ocupado por cada uma das categorias propostas. Com isso, foi possível contabilizar o espaço ocupado por cada uma das pautas em relação à totalidade do número de páginas das revistas. No levantamento, foram levadas em consideração e contabilizadas apenas as páginas ocupadas por matérias e reportagens jornalísticas, de forma que não foram levados em consideração os conteúdos publicitários, os media kits das revistas ou os publieditoriais.

Para a elaboração das categorias utilizadas na contagem, levou-se em consideração a temática da reportagem ou matéria publicada em relação ao enquadramento narrativo utilizado nas reportagens, independentemente da editoria ocupada. Por enquadramento narrativo, referimo-nos ao modo como os atores midiáticos enfatizam narrativamente determinadas partes da realidade no modo como a notícia é organizada, com enfoque a determinadas características do fenômeno noticiado em detrimento de outros (GOFFMAN, 1986; GITLIN, 2003). Em uma matéria sobre a cantora Anitta, por exemplo, destacaram-se os triunfos da cantora como empresária de êxito e, por isso, essa reportagem foi enquadrada como "história de sucesso financeiro". Tal procedimento foi utilizado em todas as reportagens analisadas.

Para a análise dos dados obtidos, utilizamos os pressupostos metodológicos da frame analysis, que tem como objetivos (1) identificar, classificar e analisar os elementos que compõem o quadro jornalístico e (2) verificar e interpretar os "quadros dominantes" das reportagens, ou seja, os enquadramentos interpretativos mais frequentes nos noticiários a partir da repetição de enquadramentos ideológicos específicos. Com isso, é possível identificar e analisar quais são os aspectos mais destacados pelos jornalistas nas publicações analisadas, bem como os quadros interpretativos da realidade mais recorrentemente aludidos por eles.

A partir desses pressupostos, o mapeamento das temáticas mais recorrentes nas três publicações analisadas de janeiro de 2017 a janeiro de 2018 compõe o seguinte quadro:

\footnotetext{
30 artigo faz parte da pesquisa de pós-doutoramento intitulada Cartografias do medo na imprensa e as masculinidades: convocações da virilidade no jornalismo e seus universos de consumo, realizada na Universidade Estadual Paulista Julio de Mesquita Filho (UNESP).
} 
Imaginários da masculinidade bem-sucedida e as narrativas de consumo na curadoria jornalística: o medo da despossessão financeira e o

Tabela 1 - Pautas abordadas em VIP, GQ e L'Officiel Hommes

\begin{tabular}{cccc} 
Categoria & GQ & Vip & $\begin{array}{c}\text { L'officiel } \\
\text { Hommes }\end{array}$ \\
Moda & $33 \%$ & $18 \%$ & $45 \%$ \\
Histórias de pessoas com sucesso financeiro & $18 \%$ & $14 \%$ & $15 \%$ \\
Viagens de luxo & $5 \%$ & $9,5 \%$ & $9,5 \%$ \\
História de marcas ou empresas de sucesso & $2 \%$ & $8,5 \%$ & $4 \%$ \\
Produtos de tecnologia & $4 \%$ & $6 \%$ & $3,5 \%$ \\
Carros, motos ou barcos & $8,5 \%$ & $6 \%$ & $0 \%$ \\
Dicas para obtenção de sucesso financeiro & $1 \%$ & $5 \%$ & $0 \%$ \\
Tendências de consumo (perfumes, drinks, design) & $4 \%$ & $11 \%$ & $6 \%$ \\
Dicas culturais, de relacionamento ou saúde & $9 \%$ & $12,5 \%$ & $3,5 \%$ \\
Ensaio com mulheres bonitas & $6 \%$ & $6,5 \%$ & $0 \%$ \\
Histórias de pessoas de sucesso (em outras áreas que não a & $9 \%$ & $2 \%$ & $12,5 \%$ \\
financeira - cultural, política etc.). & & & \\
Outros & $0,5 \%$ & $1 \%$ & $1 \%$ \\
\hline Fonte: Elaborado pela autora. & & &
\end{tabular}

É importante ressaltar que o mapeamento contabilizou apenas as reportagens jornalísticas - o material publicitário não foi levado em consideração no recorte analisado. Não se trata, portanto, de propagandas, mas de curadoria jornalística de produtos para o consumo, nos termos já explicitados anteriormente.

O mapeamento revela que as três publicações têm como temática central os editoriais e dicas de moda, seguidos pelas histórias de pessoas com sucesso financeiro presentes em maior destaque se comparadas a histórias de pessoas de sucesso em outras áreas que não a financeira (como a cultural, artística, política etc.). Ao passo que, em VIP as histórias de sucesso financeiro perfazem $14 \%$ do espaço total da revista no período analisado, as histórias de pessoas de sucesso em outras áreas ocupam apenas 2\%. Em GQ, histórias pessoais de sucesso financeiro estão em 18\% das páginas, enquanto o sucesso em outras áreas ocupa metade disso (9\%). Em L'Officiel Hommes, a relação é mais equilibrada, com $15 \%$ e 12,5\%, respectivamente. Assim como as pessoas de triunfo financeiro, as marcas e empresas de sucesso (nos negócios) também ocupam um espaço relevante nas publicações.

As temáticas relacionadas diretamente à curadoria de universos de consumo de luxo - como moda, viagens, produtos de tecnologia, carros, motos e barcos sofisticados, perfumes, drinks da moda e produtos de design - perfazem a maior parte das pautas nas 
Imaginários da masculinidade bem-sucedida e as narrativas de consumo na curadoria jornalística: o medo da despossessão financeira e o elogio à potência em VIP, GQ e L'Officiel Hommes

três publicações: a saber, com $54,5 \%$ do espaço da revista $G Q, 50,5 \%$ de VIP e $64 \%$ em L'Officiel Hommes. A curadoria de outras temáticas relacionadas ao universo masculino (mas não vinculadas diretamente a universos de consumo) como dicas culturais, de relacionamento ou de saúde, em conjunto, ocupam, em contrapartida, um espaço muito menor: $9 \%, 12,5 \%$ e $3,5 \%$, respectivamente.

A partir desses dados, é possível inferir que os eixos temáticos relativos à manutenção do poder econômico (que abarca as pautas sobre consumo, histórias de sucesso financeiro e dicas de como ganhar dinheiro) compõem a espinha dorsal a partir do qual os projetos editoriais de tais publicações são pensados. Em conjunto, tais pautas ocupam 75,5\% do espaço em GQ, 78\% em VIP e 83\% em L'Officiel Hommes no período analisado.

A partir de um olhar que toma as três publicações não a partir da fragmentação de suas partes em reportagens pontuais, mas como um entrelaçamento de discursos mais amplos que formam uma unidade editorial, é possível afirmar que elas fazem a mediação de um determinado conjunto de afetos, conectados a dinâmicas do imaginário social mais vastas. Embora o termo imaginário seja bastante amplo e se refira a diferentes filiações teóricas, nos referimos, no presente artigo, ao sentido de imaginário como um conjunto de representações sociais estruturantes que proporcionam a um determinado grupo social a designação de seus aspectos identitários, suas partilhas de papéis e funções sociais, suas expressões de crenças comuns e modelos, conferidas a partir de relações de sentido (BACZKO, 1991). Trata-se, portanto, de uma dimensão formadora do social através da qual as representações sociais a respeito de um determinado grupo são elaboradas a partir de aspectos simbólicos que são mediados e validados socialmente.

Dentre os diversos discursos e práticas (editorais, sociais e culturais) que orientam a mediação desse "lifestyle masculino" nas três publicações analisadas (e que, consequentemente, se materializam em suas narrativas), os afetos relacionados ao medo da despossessão financeira ocupam uma centralidade. Nolasco (1993, p. 103-104) parte da tese de que "[...] a prosperidade do sistema capitalista [depende ...] da manutenção dos valores e do modelo de comportamento dos homens [...]", de forma que há um determinado imaginário social da masculinidade que vincula o ser homem ao imperativo do sucesso financeiro, a partir da reprodução dos valores sociais vigentes. As narrativas das revistas aludidas, portanto, apropriam-se de tal ideário de masculinidade, correlacionando, na quase totalidade das pautas abordadas, o sucesso no mundo econômico à conquista de bens de 
Imaginários da masculinidade bem-sucedida e as narrativas de consumo na curadoria jornalística: o medo da despossessão financeira e o elogio à potência em VIP, GQ e L'Officiel Hommes

consumo extraordinários e, como seu avesso narrativo, a despossessão econômica como exclusão de acesso a tais possibilidades.

Trata-se, contudo, de um medo que não é posto a partir de paixões negativas, mas a partir de emoções positivas, articuladas nas histórias de sucesso e nas narrativas de consumo expostas em função e a partir dessas biografias. A exploração das paixões positivas é, inclusive, uma característica editorial importante das três revistas analisadas. Segundo Monteiro (2001), isso aparece em todas as pautas dessas publicações, de forma que, ao tratar do tema do corpo ou da saúde, por exemplo, não se deve focalizar a doença, mas sim, as formas de manter e recuperar a saúde. "[...] se na Veja exploram os aspectos da doença e dos males que ela pode causar, como o câncer, a VIP aborda esses aspectos de maneira mais bem-humorada, ainda que informativa." (MONTEIRO, 2001, p. 243).

O medo da despossessão financeira, em VIP, GQ e L'Officiel Hommes está articulada, fundamentalmente, a partir da exploração emotiva indireta de uma certa ansiedade social relacionada à preocupação de um indivíduo em perder uma oportunidade importante, uma experiência inovadora ou um acontecimento gratificante (em uma exploração editorial de um enquadramento narrativo publicitário que, já há algum tempo, é chamada de FOMO, fear of missing out). Relaciona-se, sobretudo, ao medo de exclusão social pela não-participação de uma série de atividades de consumo relevantes, em função da impossibilidade de arcar financeiramente por elas. As histórias de sucesso financeiro articuladas às possibilidades de consumo apresentadas pelas revistas dão visibilidade a elementos que se vinculam "[...] à atualidade do capitalismo onde o homem deve ser um empreendedor de si mesmo, desenvolvendo competências que valorizem o seu biocapital e abandonando hábitos que o depreciem." (TUCHERMAN, 2012, p. 315). Além disso, associam-se a paixões positivas “[...] cujas palavras-chave seriam: autoestima, autoconhecimento, bem estar e felicidade [...]", guiados por elementos "[...] de natureza pragmática, identificado por sucesso, dinheiro, prestígio, beleza e saúde." (TUCHERMAN, 2012, p. 315). A narrativa articulada pelas três publicações resume-se à noção de que o indivíduo conectado a tais valores pode obter uma masculinidade bem-sucedida traduzida em bem-estar financeiro e a acesso a bens de consumo de luxo.

Posto que não existe poder "[...] sem uma forma de regulagem dos corpos e de seus regimes de desejo [...]” e, assim, “[...] não há poder que não crie uma 'vida psíquica' através das marcas que deixa nos corpos." (SAFATLE, 2016, p. 136), as revistas estudadas 
Imaginários da masculinidade bem-sucedida e as narrativas de consumo na curadoria jornalística: o medo da despossessão financeira e o

demarcam universos afetivos relacionados ao consumo de luxo que remetem, em todas as suas narrativas, ao homem bem-sucedido financeiramente.

0 papel das narrativas inspiracionais, na publicização do ideário da sociedade empreendedora, é um dos elementos centrais articulados ao medo da despossessão financeira e já bastante mapeado nos estudos de comunicação (CASAQUI, 2017; EHRENBERG, 2010). Nesse artigo, iremos nos aprofundar em outros dois elementos que constituem dinâmicas sociais próprias a esse imaginário: o medo da perda da autonomia e sua resolução na paixão autoconsumptiva relacionada a universos de consumo.

\section{0 medo da perda da autonomia como eixo estruturante do imaginário da masculinidade}

"Uma sociedade não define apenas sistemas de normas a serem seguidos. Uma sociedade define principalmente modos de sofrimento diante das normas que ela mesma enuncia." (SAFATLE, 2016, p. 186). É por isso que o sofrimento é uma “[...] experiência de reconhecimento intersubjetivo [posto que] o sofrimento se partilha e é em função direta dos atos de reconhecimento que o determinam como tal." (DUNKER, 2015, p. 25). Ele é estruturado, portanto, pela narrativa e pelo discurso em que está incluído. Dentre os sofrimentos compartilhados pelas revistas analisadas, a perda da autonomia em função da despossessão financeira é um dos eixos do imaginário da masculinidade aludidos nas narrativas das revistas analisadas.

Sobre essa questão, “[...] lembremos que, nas sociedades capitalistas, o trabalho foi pensado como uma das versões mais bem-acabadas de certo processo moral de formação em direção ao autogoverno [, sendo] um fator decisivo na constituição da noção moderna de autonomia." (SAFATLE, 2016, p. 164). O sucesso financeiro, nesse sentido, se converte em um dos pilares que garantem a liberdade do sujeito posto que "[...] só aqueles capazes de trabalhar são autônomos; não apenas no sentido material de serem capazes de prover seus próprios sustentos, mas no sentido moral de serem capazes de impor a si mesmo uma lei de conduta que é expressão de sua vontade." (SAFATLE, 2016, p. 164).

Trabalhamos não apenas para ser reconhecidos enquanto sujeitos dotados de certas habilidades importantes para a vida social [, mas sim,] trabalhamos para ser reconhecidos por um Outro que habita nossas 
fantasias, que nos observa como se estivéssemos em um panóptico privado [que] nos chama para assumir um tipo de relação com os desejos e com a vontade que funda a idealidade de nossa personalidade (SAFATLE, 2016, p. 165).

O sujeito que trabalha é, assim, portador de uma série de qualidades vistas como socialmente positivas e valorizadas - sendo a autonomia conquistada um dos valores mais enaltecidos. Isso posto, é possível notar que o valor da autonomia é condecorado em vários momentos nas narrativas das revistas estudadas. É uma questão recorrentemente evocada, enquanto enquadramento narrativo, nas histórias de sucesso financeiro. Em uma reportagem que traçava o perfil de Steve Jobs e Elon Musk, por exemplo, VIP colocava que eles eram "dois geniozinhos precoces e impopulares na escola" pois "Musk sofria bullying, às vezes violento. Já Jobs não tinha paciência para colegas da mesma idade e se isolava." (OROZCO, 2017, p. 18). 0 sucesso financeiro, nas narrativas das revistas estudadas, é o resultado do trabalho de homens e mulheres que souberam dobrar as vicissitudes do mundo à sua vontade; que tiveram disciplina e discernimentos suficientes para exercer sua autonomia mesmo diante das intempéries da vida. A autonomia, nesse sentido, funciona nas narrativas dessas revistas como o eixo estruturante de uma série de valores sociais tidos como positivos e valorizados.

A autonomia aparece como valor também nos textos que aludem às expectativas geradas em torno do novo homem, que não mais se enquadra no estereótipo do macho dominante. Recorrentemente, nas revistas estudadas, é possível encontrar textos que remetem aos novos comportamentos masculinos em campos que seriam, estereotipicamente, femininos. No editorial de outubro de 2017, por exemplo, o editor de VIP, Ivan Padilla, escrevia que:

[...] a mulher tem ocupado novos espaços, ainda bem, mostrando que gênero pode ser muito mais uma construção cultural do que o domínio dos genes. Enquanto isso, o homem tem se aventurado, e não é de hoje, por um dos territórios pretensamente femininos - no caso, a cozinha. (PADILLA, 2017b, p. 8).

Aqui, como em outros textos, fica clara a valorização da autonomia como forma de exercício da vontade do indivíduo e, principalmente, como umas das maneiras de exercer a 
Imaginários da masculinidade bem-sucedida e as narrativas de consumo na curadoria jornalística: o medo da despossessão financeira e o

masculinidade. Nesse sentido, o imaginário da masculinidade bem-sucedida comporta a narrativa de que o indivíduo pode se aventurar em universos femininos porque essa é a sua escolha (e não um imperativo genético ou cultural), ou seja, um exercício efetivo de sua autonomia enquanto sujeito.

Há dois eixos narrativos, portanto, a partir dos quais a autonomia é valorizada como um dos elementos estruturantes do imaginário da masculinidade bem-sucedida. Em um primeiro sentido, remete diretamente ao medo da despossessão financeira, indicando o sentido mais lato de que apenas aqueles que podem arcar com suas contas podem exercer a liberdade plena (seja pela impossibilidade de adquirir bens, seja pela sujeição a um trabalho que não permite momentos de lazer). Em um segundo sentido, remete à valorização de um certo tipo estereotípico de personagem-herói que, com a força de sua vontade, consegue dobrar os problemas do cotidiano à sua própria vontade e, com isso, obter sucesso financeiro.

Tais dinâmicas do imaginário da masculinidade bem-sucedida são mediadas por conjuntos de afetos e, dentre eles, estão bastante presentes as narrativas articuladas na heroicização do self made man. 0 imaginário da masculinidade vinculada à figura do self made man surge, segundo Kimmel (1998) na primeira metade do século XIX. Para o autor, a masculinidade dessa figura deveria ser demonstrada no mercado. Ele era um empresário, um homem de negócios. Assim "[...] esses self made man eram ausentes dos lares, cada vez mais distantes dos seus filhos, devotados ao seu trabalho em um ambiente de trabalho homossocial." (KIMMEL, 1998, p. 111). Trata-se de:

[...] uma forma de masculinidade cada vez mais ansiosa, pois requeria demonstração e prova constantes, sendo a aquisição palpável de bens uma evidência do seu sucesso. Essa ansiedade foi incitada ainda mais pela ideologia da mobilidade ascendente. (KIMMEL, 1998, p. 111)

Tal imaginário do self made man é retraduzido pelas revistas estudadas, de forma que a ênfase no valor do trabalho não se materializa mais no afastamento de outras atividades externas ao trabalho (como a família ou o lazer). Pelo contrário: a figura do workaholic, nas narrativas das revistas estudadas, é substituída pelo valor da autonomia. Em termos mais precisos, do homem que tem autonomia suficiente para poder organizar o seu tempo de forma produtiva, aproveitar o lazer e, principalmente, consumir. 0 homem 
autônomo, afinal, possui autonomia até mesmo em relação a seu próprio trabalho, não se tornando um escravo dele. 0 "homem de estilo" desenhado pelas revistas, afinal, é aquele que tem não apenas dinheiro, mas também tempo livre para aproveitar de um mercado de luxo.

Sobre esse assunto, Buonanno (2011) ressalta uma tensão presente nas narrativas biográficas contemporâneas. Ao tratar sobre o tema de um mundo pós-heróico, que não confia mais na narrativização das capacidades extraordinárias de um indivíduo, a autora explica que "A vida diária e a vida heroica parecem mesmo ser dois polos de uma antinomia que não pode ser reconciliada: não é por acaso que a jornada do herói lendário começa, ritualmente, com o seu abandono do mundo comum." (BUONANNO, 2011, p. 69). Assim,

A vida diária é o domínio da existência comum, do senso comum, de hábitos regulares e ao mesmo tempo (cada vez mais) do horizonte interno da busca por bem-estar e realizações pessoais; a vida heroica é, ao contrário, o reino das experiências únicas, das ações que são fora do comum [...](BUONANNO, 2011, p. 69).

Além disso, o heroísmo requer coragem e a exposição ao sofrimento, enquanto a vida diária:

[...] adota desejos por uma existência feliz, guiada pelos prazeres de práticas lúdicas e consumistas, recompensada pelas satisfações de relações amorosas e atividades sociais e, acima de tudo, o mais protegida possível dos acontecimentos perigosos que lembram os seres humanos de sua intolerável condição de imortalidade. (BUONANNO, 2011, p. 69).

Não obstante essa dicotomia, contudo, há a proliferação midiática do que a autora chama de "os heróis de todos os dias": "aquelas pessoas cujas ações" e sacrifícios "[...] são inequivocamente inspiradas pela consciência e por escolhas baseadas em valores [...]", atribuindo-o "[...] de forma completamente convencional a comportamentos que, ainda que admiráveis e louváveis, não são em si heroicos (por exemplo, fazer o próprio trabalho de forma honesta e escrupulosa)." (BUONANO, 2011, p. 69).

As histórias de sucesso financeiro apresentadas em VIP, GQ e L'Officiel Hommes exploram tais tensões entre o mundo heroico e não-heróico com estratégias narrativas que 
Imaginários da masculinidade bem-sucedida e as narrativas de consumo na curadoria jornalística: o medo da despossessão financeira e o elogio à potência em VIP, GQ e L'Officiel Hommes

contemporizam as tensões ali implicadas, acomodando a vida ordinária e os atos excepcionais em um todo que funciona. Os empresários, artistas e designers vitoriosos cujas biografias são tematizadas pelas publicações se aproximam bastante desses heróis do cotidiano expostos por Buonano. Eles são indivíduos capazes de esforços diários consistentes para atingir suas metas financeiras a partir de valores compartilhados como positivos socialmente. Além disso, a partir da autonomia conquistada no mundo cotidiano, são capazes de usufruir da saída desse mundo ordinário em direção ao extraordinário - que, nesse caso, materializa-se no acesso aos produtos de maior luxo, aos prazeres mais caros e às viagens mais extravagantes. As ações fora do comum traduzem-se, assim, também pelos universos de consumo a que esses personagens têm acesso.

É nesses termos que o medo da despossessão financeira e da perda da autonomia são expostos a partir de paixões positivas e vêm acompanhados do medo do não-usufruto do que seria considerado uma "boa vida".

Tal dinâmica se estrutura, em grande parte, a partir dos imperativos da utilidade, entendida como uma certa medida de tempo que tem como régua de cálculo os esforços investidos em uma dada tarefa e sua consequente eficácia produtiva (a recusa do desperdício) como um universo moral a ser seguido. "Os sujeitos racionais no interior do capitalismo [...]" são aqueles que "[...] organizam suas ações tendo em vista sua autoconservação, a manutenção de seus bens, o cálculo econômico de seus esforços [...]" (SAFATLE, 2016, p. 161) e suas formas de fruição de prazer. "Eles são aqueles que se julgam racionais por sempre submeterem sua afetividade à reflexão sobre a utilidade e a medida." (SAFATLE, 2016, p. 161). 0 medo da despossessão financeira é abordado, portanto, não de forma direta, mas sim, a partir de narrativas que valorizam um herói que soube vencer financeiramente por força de sua própria autonomia e cálculo, tendo acesso, assim, a um mundo de luxo e (para usar um termo caro a tais publicações) estilo.

A eficácia das narrativas sobre o medo da perda do sucesso financeiro (e, consequentemente, da autonomia) não se estrutura como mera coerção (levando-se em consideração, inclusive, o fato de que nenhum tipo de adesão a normas sociais está posto meramente na pressão do constrangimento). "Há sempre uma demanda de amor e reconhecimento, direcionada a um Outro fantasmático, a sustentar minha adesão muda a tais dinâmicas repressivas." (SAFATLE, 2016, p. 167), vinculado aos modos de prestígio social. Grande parte da estratégia narrativa dessas revistas masculinas está sustentada, sobretudo, em um mecanismo de superação desse medo a partir de soluções de consumo. 
Imaginários da masculinidade bem-sucedida e as narrativas de consumo na curadoria jornalística: o medo da despossessão financeira e o

Há, contudo, outra tensão que sustenta tais narrativas. Apesar do elogio da autonomia e do cálculo, tais narrativas sobre o consumo também estão articuladas ao elogio da potência e da paixão disruptiva, conforme discutiremos a seguir.

\section{A paixão desruptiva como solução para o medo nos universos de consumo}

A curadoria de consumo das revistas VIP, GQ e L'Officiel Hommes se refere fundamentalmente a produtos de luxo. Na edição 391 (de outubro de 2017), por exemplo, a revista VIP trazia uma reportagem sobre a mesa de bilhar Elite X1 Everest, toda feita de vidro e com um design inovador, cujo preço (de tão caro) não era ao menos informado pelo seu fabricante. Também reportava as novidades da IFA 2017 (uma feira em Berlim voltada a novidades em produtos de tecnologia), um guia sobre viagens cinco estrelas, os lançamentos das grifes famosas (como Louboutin), uma reportagem só sobre relógios de luxo, um guia sobre os melhores restaurantes brasileiros e sobre os carros mais caros do mundo. Acompanhado do guia de restaurantes, havia a apresentação de um ensaio fotográfico de mulheres seminuas com o seguinte mote: "Esta edição de gastronomia nos levou a visitar nosso arquivo de fotos em busca de uma combinação de temas bem específica: mulheres deslumbrantes e comida." (PADILLA, 2017 b, p. 8). Aqui também as reportagens sobre produtos e serviços de luxo são acompanhadas pela história de empreendedores de sucesso (tanto homens quanto mulheres) como: o estilo de vida de Elon Musk (da Tesla), Jeff Bezos (da Amazon), de Clarissa Giordani (CEO do grupo Saudifitness), de Poliana Botelho (lutadora de sucesso do UFC) e de Ricardo Almeida (e sua grife de ternos), só para citar alguns exemplos. Elas são permeadas, ainda, por dicas práticas como a reportagem sobre bitcoins (e os modos de ganhar dinheiro a partir deles). Trata-se de um projeto similar à de GQ que, em janeiro de 2018, trazia reportagens sobre Como ter um submarino na casa de praia ou A mochila que anda sozinha e segue você. Com uma ênfase maior nas reportagens sobre moda masculina, trata-se da mesma proposta da versão brasileira de L'Officiel Hommes.

A masculinidade bem-sucedida das revistas analisadas, portanto, passa pelo consumo de produtos de luxo. De forma mais evidente em GQ e VIP, é importante destacar que há uma construção narrativa que diferencia o consumo masculino do feminino. No 
Imaginários da masculinidade bem-sucedida e as narrativas de consumo na curadoria jornalística: o medo da despossessão financeira e o elogio à potência em VIP, GQ e L'Officiel Hommes

discurso dessas revistas, "O homem moderno deve se preocupar com o corpo, com sua aparência, mas esta preocupação só faz sentido tendo em vista sua relação com a mulher." (MONTEIRO, 2001, p. 246). Assim, “[...] até mesmo os cosméticos têm que ser 'adaptados' para serem considerados próprios para o uso dos homens." (MONTEIRO, 2001, p. 246), relacionando-se com um suposto universo de representações dos leitores a partir do qual os homens querem agradar as mulheres (e não se tornarem parecidos com elas). "Ao mesmo tempo em que estimulam o conhecimento dos homens sobre beleza e cosméticos e a incorporação desses produtos no cotidiano, a revista os apresenta de maneira que não desestabilizem a separação entre homem e mulher." (MONTEIRO, 2001, p. 246). Assim, não se trata de um homem que supostamente se feminiliza ao usar cosméticos, mas sim, "[...] os cosméticos se masculinizam, para manter intactas as divisões entre os gêneros." (MONTEIRO, 2001, p. 246).

Para além de uma convocação ao consumo que se articula a partir da construção de um leitor ideal que se preocupa com moda e beleza sem deixar de ser másculo, há um outro elemento estruturante que urde a masculinidade bem-sucedida em tais narrativas e está mais diretamente correlacionado ao medo da despossessão financeira: trata-se do elogio à potência.

Sobre isso, é necessário enfatizar que a gestão dos afetos implicados no medo da despossessão financeira e da perda da autonomia implica em uma administração específica de desejos. A sociedade, organizada a partir do imperativo da circulação de bens, é aquela que determina as ações do sujeito a partir da produção de valor, de forma que "[...] precisa socializar o desejo levando-o a ser causado pela pura medida da intensificação, pelo puro empuxo à ampliação que estabelece os objetos de desejo em um circuito incessante e superlativo chamado por Lacan de mais-gozar." (SAFATLE, 2016, p. 142). Trata-se de uma “[...] economia psíquica não mais assentada em um supereu repressivo, mas em um supereu que eleva o gozo à condição de imperativo transcendente." (SAFATLE, 2016, p. 142). Ou, em outros termos, tal como apontado por Prado (2013), “[...] na sociedade de controle, a biopolítica penetra nos dispositivos midiáticos, não a partir de um supereu repressor, mas de um supereu que incita o gozo." (PRADO, 2013, p. 163).

A administração de si, nesse contexto, deve seguir os imperativos de uma maximização da performance do indivíduo, calcada em uma flexibilização contínua das normas. "O sujeito neoliberal é muito mais um agente calculador de custos e benefícios do que um sujeito de quem se espera a conformação às normas sociais. Ele não segue normas 
Imaginários da masculinidade bem-sucedida e as narrativas de consumo na curadoria jornalística: o medo da despossessão financeira e o elogio à potência em VIP, GQ e L'Officiel Hommes

positivas, mas calcula resultados e, por isso, flexibiliza normas continuamente." (SAFATLE, 2016, p. 143). Uma das consequências desse processo é que a concorrência passa a ser o motor central do laço social, de forma que "[...] a violência contra o outro se converte em violência contra as formas e normas que pareciam determinar o outro e que permite ultrapassá-lo." (SAFATLE, 2016, p. 144). É evidente que a narrativização das biografias dos homens de sucesso de VIP, GQ e L'Officiel Hommes estão conectadas a esses valores de performance otimizada do indivíduo, administração de si e concorrência como laço social.

No caso da curadoria dos produtos de luxo, contudo, tais valores se mostram de uma maneira um pouco diferente daquela implicada nas biografias. Não se trata apenas, aqui, de dar visibilidade a características tidas como socialmente validadas da masculinidade bemsucedida a partir de sua materialização em histórias de sucesso, mas de conectar tais valores aos produtos anunciados a partir de um elogio à potência como eixo narrativo articulador desses mesmos valores. Os valores relativos à maximização do indivíduo são incorporados, assim, pelos próprios objetos escolhidos pela curadoria das revistas em um espelhamento objeto-indivíduo, conforme discutiremos a seguir.

Sobre essa questão, é necessário considerar que, para Sennett (2006), grande parte da estruturação social do ciclo de consumo está alicerçada em uma paixão autoconsumptiva: "Na linguagem poética, uma paixão comsumptiva pode ser uma paixão que se extingue na própria intensidade [...]" (SENNETT, 2006, p. 128). No que se refere aos universos de consumo isso significa que "Nosso desejo de determinada roupa pode ser ardente, mas alguns dias depois de comprá-la e usá-la, ela já não nos entusiasma tanto." (SENNETT, 2006, p. 128). Assim, "Nesse caso, a imaginação é mais forte na expectativa, tornando-se cada vez mais débil com o uso. A economia de hoje reforça essa espécie de paixão autoconsumptiva, tanto nos shoppings centers quanto na política." (SENNETT, 2006, p. 128).

A convocação ao consumo nas revistas analisadas estrutura-se a partir dessa participação na cultura da paixão autocomsumptiva, na medida em que os editores não esperam, necessariamente, que os seus leitores-ideais comprem os produtos de luxo anunciados nas reportagens (como a mesa de bilhar de vidro, por exemplo que, ademais, deve ser bem pouco prática para a vida cotidiana) ou façam as viagens suntuosas expostas de maneira quase banal. 0 mecanismo de convocação opera pela evocação de um desejo fantasmático que se estrutura enquanto expectativa e que não espera uma efetiva realização. 
Imaginários da masculinidade bem-sucedida e as narrativas de consumo na curadoria jornalística: o medo da despossessão financeira e o elogio à potência em VIP, GQ e L'Officiel Hommes

Conjuntamente a esse mecanismo, está implicado o elogio constante à potência. "A potência é algo que podemos comprar [...]" (SENNETT, 2006, p. 139). E isso significa que "Já é de senso comum na indústria eletrônica que os consumidores comuns compram equipamentos com possibilidades que jamais utilizarão [...]"(SENNETT, 2006, p. 139), como discos de memórias capazes de armazenar 400 livros ou um milhão de músicas - muito mais do que a maioria das pessoas irá ler ou ouvir em uma vida inteira. "E, no entanto, o fenomenal atrativo comercial do iPod consiste precisamente em dispor de mais do que uma pessoa jamais seria capaz de usar." (SENNETT, 2006, p. 141). A não possibilidade de utilização é o que garante o vínculo a um desejo permanente - que, por sua vez, é aproveitado pelas revistas masculinas como um mecanismo de convocação ao consumo bastante eficiente, uma vez que anunciam produtos com uma grande valência de potência (para atrair o desejo) e pouca de realização (para que esse nunca se materialize).

É nesse sentido que “[...] vivemos hoje em uma sociedade na qual os vínculos com os objetos (incluindo aqui os vínculos com a imagem do próprio corpo) são frágeis, mas que, ao mesmo tempo, alimenta-se dessa fragilidade." (SAFATLE, 2016, p. 156).

O sucesso do apelo se estrutura, para Sennett (2006), na ligação entre a potência material e a suposta aptidão potencial direcionada ao sujeito desejante. Há, portanto, uma triangulação identitária entre a potência contida nos objetos de consumo e as aptidões em potência do próprio indivíduo que possui (imaginariamente) esses objetos. Trata-se, portanto, de uma articulação do imaginário mais ampla que estrutura a cultura do consumo em uma variedade de estruturações imaginárias e sociais distintas (e da qual o jornalismo, como prática discursiva, participa). Assim, "O caçador de talentos está menos interessado naquilo que sabemos, e mais no quanto seríamos capazes de aprender; o diretor de pessoal está menos interessado no que já fazemos do que naquilo que podemos nos transformar." (SENNETT, 2006, p. 141). Comprar um iPod significa, para Sennett (2006), participar dessa cultura do que podemos nos transformar. E, assim, “[...] todas as máquinas dessa espécie jogam com a identificação do comprador com o excesso de capacidade nelas contido." (SENNETT, 2006, p. 142).

Da mesma forma, os produtos e viagens ostensivamente caros expostos nas reportagens da VIP, GQ e L'Officiel Hommes não estão ali apenas para informar sobre as novidades do mercado de tecnologia ou para comunicar dicas sobre os melhores destinos. 0 jornalismo se desloca de sua tarefa informativa e passa a atuar como um dos atores no elogio à potência (ou, em outros termos, às potencialidades de um indivíduo desejante), ao 
que esse sujeito (imaginariamente) pode vir a ser. Os produtos resultantes da curadoria jornalística, nesse sentido, materializam os valores de uma masculinidade bem-sucedida, ou seja, do que esse homem-leitor-ideal pode também vir a ser, encarnando um elogio de sua própria potência.

Em termos mais abstratos, “[... o desejo é mobilizado quando a potência é divorciada da prática [...]" (SENNETT, 2006, p. 142). Quanto mais distantes das possibilidades reais da vida vivida, maior é a efetividade do mecanismo de convocação ao consumo, já que é o desejo irrealizável que estrutura a própria potência.

Trata-se de uma estratégia de convocação historicamente marcada, bastante específica de um tipo de cultura de consumo. Sennett (2006) aborda a questão nos seguintes termos:

Existe um contraste, nesse sentido, entre a Wal-Mart e as primeiras lojas de departamento que surgiram em Paris no fim do século XIX. Nesses empórios comerciais, o marketing consistia em exibir um grupo de objetos diferentes, dois de cada, no mesmo espaço; por exemplo, podia-se ver uma caçarola sobre um tapete persa, perto de um frasco de perfume fino. 0 comerciante pretendia estimular o comprador, tornado estranho o que é comum, ao passo que na Wal-Mart o que estimula é pura e simplesmente o número e o excesso de objetos. (SENNETT, 2006, p. 142)

O estímulo à paixão consumptiva através da incitação à potência também é um tema tratado por Safatle, em uma análise de uma cena de Cosmópolis. Em um determinado momento, um dos personagens diz:

O que você comprou por 104 milhões de dólares? Não foram dezenas de cômodos, vistas incomparáveis, elevadores privados. Nem o quarto rotativo nem a cama computadorizada. Nem a piscina nem o tubarão. 0 espaço aéreo? Os sensores de controle e o software? Não, nem os espelhos que dizem como se sente quando olham para eles de manhã. Você gastou esse dinheiro pelo número em si. Cento e quarenta milhões. Foi isso que você comprou. E valeu a pena. (SAFATLE, 2016, p. 134).

A partir dessa cena, Safatle (2016) remete ao fato de que a disciplina neoliberal não se configura apenas como um conjunto de condições para a internalização de dinâmicas 
repressivas, mas como um processo em que a dinâmica pulsional é absorvida pela lógica econômica "[...] através de uma socialização das pulsões que não passe mais, de forma hegemônica, pelas clivagens organizadas em forma do recalque." (SAFATLE, 2016, p. 138). 0 trecho de Cosmópolis para Safatle (2016), explicita que a cultura do consumo está alicerçada no "[...] empuxo à ampliação financeiramente mensurável que destrói todo e qualquer objeto, que faz com que objetos sejam apenas os suportes de sua própria mensuração." (SAFATLE, 2016, p. 143).

É nesse sentido que o gozo aludido nas publicações está sempre sob os imperativos da potência: dos gastos cada vez mais luxuosos, das viagens cada vez mais impressionantes e das tecnologias cada vez mais caras. 0 superlativo do luxo é, portanto, um aspecto central das estratégias de convocação a partir da alusão a aspectos do imaginário social mais amplos. Nesse ponto, é importante lembrar que:

[...] o gozo é irredutível ao valor, ou seja, é aquilo que está dentro do sistema de trocas com valor zero, mas está fora do valor. Tanto na esfera da política quanto no psiquismo, trata-se sempre de lidar com isso que está a mais, localizando-o, cercando-o pela linguagem. (PRADO, 2013, p. 24).

O imaginário da masculinidade bem-sucedida aqui, portanto, está conectado a um sucesso do vir-a-ser do próprio indivíduo em sua relação imaginária com os produtos. 0 inatingível e a potência, inclusive, elevam-se à categoria de um valor moral, de forma que definem uma certa forma da masculinidade bem-sucedida.

\section{Considerações finais}

O imaginário da masculinidade bem-sucedida na imprensa comporta uma série de elementos dos quais o medo da despossessão financeira e o elogio à potência em universos de consumo constituem componentes importantes. Tanto em VIP quanto em GQ e L'Officiel Hommes, o projeto editorial urde um complexo afetivo a partir do qual a apreensão quanto ao não-pertencimento ao universo dos homens de êxito se estrutura narrativamente a partir da remissão a paixões positivas, e não a sentimentos negativos. Assim, o medo da despossessão financeira não aparece de forma mais óbvia (como em reportagens sobre o 
desemprego ou sobre a perda de ativos, por exemplo), mas a partir de uma exibição da biografia de indivíduos com sucesso financeiro e de uma curadoria de produtos e serviços de luxo que tal triunfo pode ocasionar. Ela se materializa em histórias de sucesso que remetem à fantasia dos aspectos de uma vida que pode ser vivida de forma autônoma tanto do ponto de vista da autodeterminação do sujeito quanto da liberdade para o usufruto de bens e serviços caros - sentida como a expressão de sua própria vontade.

Atrelado a esse aspecto, está o elogio à potência que se materializa na curadoria de produtos de luxo. Há, nesse sentido, uma convocação ao consumo estruturada a partir do estímulo à paixão consumptiva e ao gozo proporcionado por produtos com uma grande valência de potencialidade financeira (para atrair o desejo) e pouca de realização (para que esse nunca se materialize). Nesse sentido, Prado (2014) chama a atenção para os três aspectos centrais do gozo, sendo eles: “[...] esbanjamento (o gozo é desmedido), desaparecimento do sujeito que goza (não há aí quem responda pelo gozo) e perda do objeto (o gozo prossegue até consumir o objeto)." (PRADO, 2014, p. 88). VIP, GQ e L'Officiel Hommes estruturam seus projetos afetivos-editoriais a partir de tais dinâmicas do imaginário da masculinidade bem-sucedida, em que o gozo não se dá pelo consumo do objeto, mas pela sua potencialidade enquanto elemento que supostamente espelharia as características do próprio sujeito desejante.

\section{Referências}

BACZKO, Bronislaw. Los imaginários sociales: memorias y esperanzas coletivas. Buenos Aires: Nueva Visión, 1991.

BUONANNO, Milly. Histórias de vidas exemplares. Biografias. Matrizes, São Paulo, v. 5, n. 1, p. 63-84, jul./dez. 2011,.

CASAQUI, Vander. Abordagem crítica da cultura da inspiração: produção de narrativas e o ideário da sociedade empreendedora. E-compós, Brasília, v. 20, n. 2, p. 1-18, maio/ago. 2017.

CORREAA, Elizabeth Saad; BERTOCCHI, Daniela. O Algoritmo Curador: o papel do curador no cenário algorítmico da informação. In: ENCONTRO ANUAL COMPÓS, 21., 2012, Juiz de Fora. Anais... Juiz de Fora: Universidade Federal de Juiz de Fora, 2012. p. 1-15.

CORRÊA, Felipe Botelho. A busca por segurança: imaginário do medo e geografia urbana. Contemporânea, Rio de Janeiro, v. 8, n. 1, p. 88-105, 2010, 
Imaginários da masculinidade bem-sucedida e as narrativas de consumo na curadoria jornalística: o medo da despossessão financeira e o elogio à potência em VIP, GQ e L'Officiel Hommes

CRUZ, Ricardo França. A fantástica fábrica de listas. GQ, São Paulo, p. 28, out. 2017. Editorial. CRUZ, Ricardo França. Brasil em alta resolução. GQ, São Paulo, p. 20, jan. 2018. Editorial. DUNKER, Christian. Mal-estar, sofrimento e sintoma. São Paulo: Boitempo, 2015. EHRENBERG, Alain. 0 culto da performance. São Paulo: Idéias \& Letras, 2010. GITLIN, Todd. The whole world is watching. Berkeley: University of California Press, 2003. GOFFMAN, Erving. Frame analysis: an essay on the organization of experience. Boston: Northeastern University Press, 1986.

GQ. Media kit. São Paulo, 2017.

KIMMEL, Michael S. A produção simultânea de masculinidades hegemônicas e subalternas. Horizontes Antropológicos, Porto Alegre, v. 4, n. 9, p. 103-117, out.1998.

L’OFFICIEL HOMMES. Media kit. São Paulo, 2017.

MONTEIRO, Marko. Corpo e masculinidade na revista VIP Exame. Cadernos Pagu, Campinas, v. 1, n. 16, p. 235-266, 2001,.

MORETZSOHN, Sylvia. Imprensa e criminologia: o papel do jornalismo nas políticas de exclusão social. Biblioteca Online de Ciências da Comunicação, Covilhã, 2003.

NOLASCO, Sócrates. 0 mito da masculinidade. Rio de Janeiro: Rocco, 1993.

OROZCO, Marcelo. Os novos jobs e gates. VIP, São Paulo, p. 18, out. 2017.

PADILLA, Ivan. Summertime. Editorial. VIP, São Paulo, p. 6, jan. 2017a.

PADILLA, Ivan. Entre a solda e o crochê. Editorial. VIP, São Paulo, p. 8, out. 2017b.

PRADO, José Luiz Aidar. Convocações biopolíticas dos dispositivos comunicacionais. São Paulo: EDUC, 2013.

PRADO, José Luiz Aidar. Habermas com Lacan. São Paulo: EDUC, 2014.

SAFATLE, Vladimir. 0 circuito dos afetos: corpos políticos, desamparo e o fim do indivíduo. Belo Horizonte: Autêntica, 2016.

SENNETT, Richard. A cultura do novo capitalismo. Rio de Janeiro: Record, 2006.

TUCHERMAN, Ieda. Relações perigosas: autoajuda, mídia e biopoder. Famecos, Porto Alegre, v. 19, n. 2, p. 315-335, maio/ago. 2012.

VIP. Media kit. São Paulo, 2017. 


\title{
Imaginaries of successful masculinity and universes of consumption in journalistic curatorship: the fear of financial dispossession and the praise of potency in VIP, GQ and L'Officiel Hommes
}

\begin{abstract}
The aim of this article is to analyze the fear of financial dispossession as a structuring dynamic of the successful masculinity imaginaries in the editorial project of some contemporary male magazines, namely VIP, GQ and L'Officiel Hommes. The fear of losing economic power, in these terms, is not always seen in the most obvious places, but implies a management of positive affects that support specific consumption narratives. From an analysis of common places in financial success narratives in these journals, we can infer that the narratives of fear of financial dispossession are sustained, in these productions, by disruptive passion, the fear of losing autonomy and praise of potency as pillars that sustain such imaginaries.
\end{abstract}

\section{Keywords}

Communication. Consumption. Masculinities. Affectivity. Narratives.

Recebido em 30/01/2018

Aceito em 24/05/2018 